EGU2020-11038

https://doi.org/10.5194/egusphere-egu2020-11038

EGU General Assembly 2020

(c) Author(s) 2021. This work is distributed under

the Creative Commons Attribution 4.0 License.

\title{
Synoptic climatology and changes in precipitation associated with the South Atlantic Convergence Zone utilising a cloud band identification technique
}

Marcia Zilli and Neil Hart

University of Oxford, School of Geography and the Environment, United Kingdom of Great Britain and Northern Ireland (marcia.zilli@ouce.ox.ac.uk)

Austral wet season precipitation (October through March) in the subtropical parts of Brazil is related to the strength and position of the South American Convergence Zone (SACZ), one of the main features of the South American Monsoon System. The SACZ can be defined as the aggregation of individual tropical-extratropical (TE) cloud bands. Such TE cloud bands have deep convection and heavy rainfall linking the tropical convection over the Amazon rain forest to the mid-latitude weather systems in the Southern Ocean. Utilising a cloud band identification technique, which consists of an object-based algorithm that identifies TE interactions, we detected individual weather systems and explored their associated precipitation characteristics and changes since 1980. Each event is characterised by the total precipitation within the contour of the low-value OLR. For this, we considered three different datasets: observed precipitation from various weather stations over Brazil, gridded to a $0.25^{\circ}$ lat/lon resolution; satellite-based rainfall from TRMM (version 3B42); and reanalysis-based precipitation from ERA5. Here we explore the spatial characteristics and associated precipitation statistics of the SACZ events identified through the proposed technique. The monthly spatial signature of the selected events is similar among the three data sources and corresponds to the SACZ location. The selected events account for $25 \%$ to $50 \%$ of the total monthly precipitation during the wet season, with the largest percentages occurring in December and January. Over South-eastern Brazil, we identified a reduction in the number of events and in total precipitation during these events, resulting in a reduction of their contribution to the total precipitation climatology during the last decade. The drying trends occur mostly in December; in January, the areas with reduced precipitation migrate northward and precipitation increases over Southern Brazil, suggesting that the poleward migration of the SACZ is more pronounced during these months. These results demonstrate the relationship between synoptic systems and the changes in the location of the SACZ described in recent studies. In the next steps, we will diagnose the reanalysed and climate-simulated circulations associated with these events, identifying possible mechanisms responsible for the poleward shift of the SACZ. 